\title{
Activated iNKT cells enhance the anti- tumor effect of antigen specific CD8 T cells on mesothelin-expressing salivary gland cancer
}

Yuji Makita ${ }^{1 \dagger}$, Naoki Kunii ${ }^{1 \dagger}$, Daiju Sakurai ${ }^{1}$, Fumie Ihara', Shinichiro Motohashi ${ }^{2}$, Akane Suzuki ${ }^{2,3}$, Toshinori Nakayama ${ }^{3}$ and Yoshitaka Okamoto ${ }^{1 *}$

\begin{abstract}
Background: Salivary gland cancers are not sensitive to conventional radiotherapy or chemotherapy regimens. Therefore, the development of a new treatment strategy is of critical importance for improving the prognosis. We examined the expression of mesothelin molecules in salivary gland cancers and the efficacy of adoptive cell therapy based on mesothelin-specific chimeric antigen receptor transduced T cells.

Methods: The expression of mesothelin molecule was studied in salivary gland cancer samples obtained from 16 patients as well as a salivary gland cancer cell line (A-253) and five other cell lines. The activation of mesothelinspecific chimeric antigen receptor-expressing CD8 T cells after stimulation with mesothelin and the effects of invariant natural killer T cells on this activation were evaluated.

Results: Mesothelin was detected in the A-253 cells and the surgical specimens except for the case of squamous cell carcinoma to various degrees. Following stimulation with mesothelin expressing cancer cells, chimeric antigen receptor $T$ cells were dose-dependently activated; this activation was enhanced by co-culture with invariant natural killer T cells and subsequently abrogated by treatment with anti-interferon- $\gamma$ antibodies. Furthermore, the cytotoxicity of chimeric antigen receptor $T$ cells against various cancer cells was further augmented by invariant natural killer T cells.
\end{abstract}

Conclusions: The use of adoptive transfer with mesothelin-specific chimeric antigen receptor-expressing CD8 T cells against salivary gland cancers is an effective therapy and invariant natural killer T cells are expected to be used in adjuvant treatment for T cell-based immunotherapy.

Keywords: Adoptive immunotherapy, Chimeric antigen receptor, Cytotoxic T lymphocyte, Natural kiiler T-cells, Salivary gland cancer

\section{Background}

Salivary grand cancers (SGCs) exhibit a broad-spectrum of phenotypic, biological and clinical diversity [1, 2]. High-grade malignancies of SGCs (e.g., mucoepidermoid carcinoma (high-grade type), adenoid cystic carcinoma, salivary duct carcinoma and carcinoma ex pleomorphic

\footnotetext{
* Correspondence: yokamoto@faculty.chiba-u.jp

${ }^{+}$Yuji Makita and Naoki Kunii contributed equally to this work.

'Department of Otorhinolaryngology, Head and Neck Surgery, Graduate

School of Medicine, Chiba University, 1-8-1 Inohana, Chuo-ku, Chiba

260-8670, Japan

Full list of author information is available at the end of the article
}

adenoma, etc.) carry a poorer prognosis $[3,4]$. The first choice of clinical treatment for resectable SGC is surgical excision [5], and adjuvant radiation therapy has the potential to increase survival $[6,7]$. However, the sensitivity of most SGCs to conventional radiation therapy and chemotherapy regimens is not sufficiently certified [8]. Recently, the novel approach of radiation therapy such as intensity modulated radiation therapy (IMRT), accelerated hyperfractionated photon-beam therapy were developed to improve the local control of unresectable and recurrent salivary gland tumors [9-11].

(c) The Author(s). 2018 Open Access This article is distributed under the terms of the Creative Commons Attribution 4.0 International License (http://creativecommons.org/licenses/by/4.0/), which permits unrestricted use, distribution, and 
However, the adverse events associated with these therapies have not been fully evaluated.

Chimeric antigen receptors (CARs) are recombinant receptors with the characteristics of antibody-based specificity and the ability to trigger $\mathrm{T}$ cell activation [12-15]. Transduced CARs provide $\mathrm{T}$ cells with the properties of antigen-specific recognition, activation and proliferation, independent of their major histocompatibility complex (MHC) [12, 16, 17], and adoptive cellular therapy using redirected $\mathrm{T}$ cells with CARs is a promising immunotherapeutic strategy [18, 19]. However, the tumor-specific antigens in most cancers are not yet well defined [20], and it is thus critical to identify adequate target antigens when applying CAR-based immunotherapy clinically. One attractive tumor target is mesothelin (MSLN), a membranous glycoprotein expressed in a variety of cancers, including mesothelioma, ovarian cancer and pancreatic cancer [21-24]. MSLN-specific CARs that consist of a MSLN-specific single chain variable fragment ( $\mathrm{SS} 1-\mathrm{scFv})$ linked to the

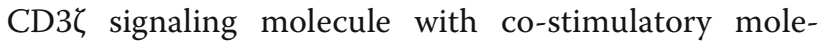
cules, such as CD28, CD137 (4-1BB) or CD278 (inducible T cell co-stimulator, ICOS), was recently produced and a clinical study of its effectiveness is ongoing [25]. Although there have been a few reports of the eradication of solid tumors with CAR-expressing T cells [26], solid tumors appear to be a less effective target for CAR-expressing $\mathrm{T}$ cells than hematological malignancies [27]. In order to apply immunotherapy regimens using MSLN-specific CAR T cells in cases of SGC, it may be necessary to develop adjuvant agents that enhance the anti-tumor activity.

Invariant natural killer T (iNKT) cells have invariant antigen receptors that recognize glycolipid antigens, such as $\alpha$-galactosylceramide ( $\alpha$ GalCer), presented by CD1d molecules [28-32]. Following activation, iNKT cells exert cytotoxic effects on a variety of cancer cells and we previously showed that activated iNKT cells and $\alpha$ GalCer-loaded dendritic cells (DCs) reduce the tumor volume in patients with head and neck squamous cell carcinoma (HNSCC) in clinical studies [33-36]. It has been reported that large amount of interferon- $\gamma$ (IFN $\gamma$ ) produced by iNKT cells induce the activation of other effector cells, such as natural killer (NK) cells and cytotoxic T lymphocytes (CTLs), and these effector cells in tumor site play an important role in the expression of the anti-cancer effects [37, 38]. However, the experiments about these activation mechanisms between iNKT cells and CTLs had not been performed because it was difficult to prepare the antigen specific $\mathrm{T}$ lymphocyte at high purity.

In this report, we confirmed that most of SGC specimens expressed MSLN molecule. In addition, we demonstrate that the IFN $\gamma$ produced by iNKT cells augments the cytotoxicity of CTLs against MSLN-expressing cancer cells using MSLN-specific CAR T cells, and moreover discussed the feasibility of adoptive cell therapy for SGC using the combination of MSLN-specific CAR-expressing T cells and iNKT cells.

\section{Methods}

Construction of the anti-MSLN CAR and vector production The pELNs vector-based third-generation MSLN-targeted CAR, constructed using MSLN-specific SS1-scFv with or without CD28, 4-1BB and the CD3 signaling domains (SS1-28-BB- $\zeta$ or SS1- $\Delta \zeta$ ) were transfected into 293 T cells using FuGENE HD reagent according to the manufacturer's protocol (Promega, Madison, WI) [25]. The method for generating the lentivirus supernatant has been described previously [39].

\section{Cell lines}

A-253 cells (HTB- $41^{\mathrm{TM}}$ ) derived from epidermoid carcinoma of the submaxillary salivary gland and FaDu cells $\left(\right.$ HTB $\left.-43^{\text {тx }}\right)$ derived from hypopharyngeal squamous cell carcinoma (SCC) were purchased from ATCC (Manassas, VA), and IMC-3 cells derived from maxillary sinus SCC were kindly provided by Dr. N. Seki, Chiba University. M108 cells derived from the malignant pleural effusion of a mesothelioma patient and MSLN-transduced K562 (K562-MSLN) cells were kindly provided by Dr. C. H. June, University of Pennsylvania [25]. The A-253 cells were maintained with McCoy's 5a Medium (ATCC) containing $10 \%$ fetal bovine serum (FBS). The IMC-3 cells and K562-MSLN cells were cultured in RPMI 1640 (Life Technologies Japan, Tokyo, Japan) with 10\% FBS and the FaDu cells were subcultured in DMEM (Life Technologies Japan) with 10\% FBS.

\section{Preparation of iNKT cells and CAR-transduced CD8 T cells} iNKT cells of high purity were generated as previously described [34, 40]. Briefly, peripheral mononuclear cells (PBMCs) were separated via density gradient centrifugation using Ficoll-Paque PLUS (GE Healthcare Life Science, Pittsburgh, PA) and cultured in the presence of $100 \mathrm{U} / \mathrm{mL}$ of recombinant human IL-2 (rhIL-2, Imunace; Shionogi, Osaka, Japan) and $100 \mathrm{ng} / \mathrm{mL}$ of $\alpha \mathrm{Gal}-$ Cer (REGiMMUNE, Tokyo, Japan). After seven days of culture, the V $\alpha 24$-positive iNKT cells were purified using the MACS separation system (Miltenyi Biotec, Bergisch Gladbach, Germany) and incubated for an additional seven days.

CD8 T cells were isolated from the peripheral blood via negative selection using RosetteSep Human CD8 T Cell Enrichment Cocktail (STEMCELL Technologies INC., Vancouver, Canada) and stimulated with Dynabeads Human T-Activator CD3/CD28 (Life Technologies Japan) 
at a bead-to-cell ratio of 1:1 in medium supplemented with $300 \mathrm{U} / \mathrm{mL}$ of rhIL-2. Lentiviral vector supernatant of $\mathrm{SS} 1-\Delta \zeta$ or $\mathrm{SS} 1-28-\mathrm{BB}-\zeta$ was added at $24 \mathrm{~h}$ after the initial stimulation. The CAR T cells were expanded for 10 days and subsequently used for the experiments.

All specimens were collected according to the Chiba University Institutional Review Board-approved protocol (No.1016), and written informed consent was obtained from each donor.

\section{Flow cytometric analysis}

In order to detect iNKT cells and CAR-expressing CD8 $\mathrm{T}$ cells, the following antibodies were used: anti-V $\alpha 24$, V $\beta 11$ (Beckman Coulter, Brea, CA), anti-CD8 (BD Biosciences), biotin-labeled polyclonal goat anti-mouse $\mathrm{F}(\mathrm{ab}) 2$ antibodies (Jackson ImmunoResearch, West Grove, PA), streptavidin-APC (BD Biosciences) and anti-human MSLN (R\&D Systems, Minneapolis, MN). Dead cells were stained with 7-aminoactinomycin D (7AAD; BD Bioscience). The fluorescence intensity was measured using the FACSCanto II instrument (BD Bioscience), and the data were analyzed with the FlowJo software program (Tree Star, Ashland, OR).

\section{Tissue preparation, immunohistochemistry and quantitative RT-PCR}

Tissue samples were obtained from surgical specimens harvested from patients with salivary gland tumor who underwent tumor resection at Chiba University Hospital, Chiba, Japan. The study protocol was approved by the Institutional Ethics Committee (no. 1336) and conformed to the provisions of the Declaration of Helsinki, 1995. In addition, written informed consent was obtained from all patients prior to surgery.

Tissue fixation and preparation and staining of the tissue sections were performed as previously described [41]. Anti-human mesothelin mouse monoclonal antibodies (Novocastra clone 5B2; Leica, Buffalo Grove, IL), Alexa Flour 594-conjugated goat anti-mouse IgG (Life Technologies Japan) and DAPI (Dojindo, Kumamoto, Japan) were used for staining. All histological analyses were carried out using a confocal laser microscope (LSM710; Carl Zeiss, Oberkochen, Germany). MSLN expressing cells were counted by fluorescence microscopy and classified into 5 groups $(-$, stained cells $<5 \%$; $1+, 5-20 \% ; 2+, 20-50 \% ; 3+, 50-70 \% ; 4+,>70 \%)$. The tumor tissues of an oncocytoma and pleomorphic adenoma were used as positive and negative control. One well-experienced pathologist, who acted completely independently of this study, histologically diagnosed the tissues.
The relative expression of MSLN were measured by quantitative RT-PCR as described previously [35]. Primers specific for the constant region of the MSLN (sense, GAATGTGAGCATGGACTTGG; antisense, ACGTGGGGTCCCAGAAGT) were used to detect the MSLN molecule of the surgical specimens. All quantitative RT-PCR studies were performed using the Lightcycler 480 II instrument (Roche Applied Science, Indianapolis, IN). The expression was normalized using the GAPDH.

\section{CD107a mobilization assay}

The CD107a mobilization assay was performed as previously described [42]. Briefly, $1 \times 10^{6}$ of M108, A253, IMC3 and FaDu target cells were incubated in each well of a 96-well flat bottom plate overnight in order to adhere the cells to the bottom of the plate. K562-MSLN cells were also incubated overnight. A total of $1 \times 10^{6}$ CAR T cells with or without $3 \times 10^{6}$ of iNKT cells and $\alpha$ GalCer-loaded antigen-presenting cells (APCs) and $10 \mu \mathrm{L}$ of CD107a-PE antibodies (BD Biosciences) were added to each well. In order to turn off the effects of IFN $\gamma, 5 \mu \mathrm{g}$ of anti-human IFN $\gamma$ antibodies (BioLegend, San Diego, CA) was added. Two microliters of monensin (eBioscience) was spiked and the cells were collected after $3.5 \mathrm{~h}$ of incubation. Finally, the cells were stained with anti-mouse IgG, V $\alpha 24$, streptavidin, CD8 and 7AAD and analyzed using flow cytometry.

Table 1 MSLN expressions in the surgical specimens with various pathological diagnosis of SGC

\begin{tabular}{|c|c|c|}
\hline Pathological diagnosis & $\begin{array}{l}\text { Mesothelin } \\
\text { expression }^{a}\end{array}$ & Case \\
\hline Salivary duct carcinoma & $3+$ & 1 \\
\hline Salivary duct carcinoma & $1+$ & 3 \\
\hline Salivary duct carcinoma & $1+$ & 4 \\
\hline Salivary duct carcinoma & $3+$ & 15 \\
\hline Salivary duct carcinoma & $3+$ & 16 \\
\hline Mucoepidermoid carcinoma & $3+$ & 5 \\
\hline Mucoepidermoid carcinoma & $2+$ & 7 \\
\hline Mucoepidermoid carcinoma & $3+$ & 9 \\
\hline Mucoepidermoid carcinoma & $4+$ & 12 \\
\hline Adenoid cystic carcinoma & $3+$ & 6 \\
\hline Adenoid cystic carcinoma & $4+$ & 11 \\
\hline Adenocarcinoma & $4+$ & 13 \\
\hline Adenocarcinoma & $2+$ & 14 \\
\hline Acinic cell carcinoma & - & 2 \\
\hline Acinic cell carcinoma & $2+$ & 10 \\
\hline Squamous cell carcinoma & - & 8 \\
\hline Pleomorphic adenoma & - & 17 \\
\hline
\end{tabular}




\section{Cellular proliferation assay}

The cellular proliferation assay was performed as previously described [42]. Briefly, CAR T cells were stained with PKH26 dye (Sigma-Aldrich, St. Louis, MO) according to the manufacturer's protocol. CAR T cells, iNKT cells and $\alpha$ GalCer-pulsed APCs treated with or without anti-IFN $\gamma$ were supplemented with $1 \times 10^{6}$ of A-253, IMC-3, FaDu and K562-MSLN cells. After $72 \mathrm{~h}$ of incubation, the cells were collected and stained with anti-mouse IgG, anti-V $\alpha 24$, anti-CD8 and 7AAD. The fluorescence intensity of PKH26 in the CAR T cells was evaluated using flow cytometry and $\mathrm{T}(\mathrm{X})$ between 0 and $72 \mathrm{~h}$ of CAR T cells was calculated using population comparison mode in FlowJo software as previously published [43, 44].

\section{In vitro cytotoxicity assay}

A-253, IMC-3, FaDu and K562-MSLN cells were incubated with 100 of $\mu \mathrm{Ci}$ sodium chromate (PerkinElmer, Waltham, MA) for $1 \mathrm{~h}$. The CAR T cells, iNKT cells or 1 to $1 \mathrm{mix}$ tures of CAR T cells and iNKT cells treated with irradiated $\alpha$ GalCer-loaded APCs were added to ${ }^{51} \mathrm{Cr}$-labeled target cells $\left(1 \times 10^{4}\right)$ at several E: T ratios. After four hours of incubation, the supernatant was collected and the dose of radiation was measured using a Packard COBRA II Automated Gamma Counter (GMI Inc., Ramsay, MN).

\section{Statistical analysis}

Student's $t$-test was used to evaluate the significance of differences between the two groups of homoscedastic samples.
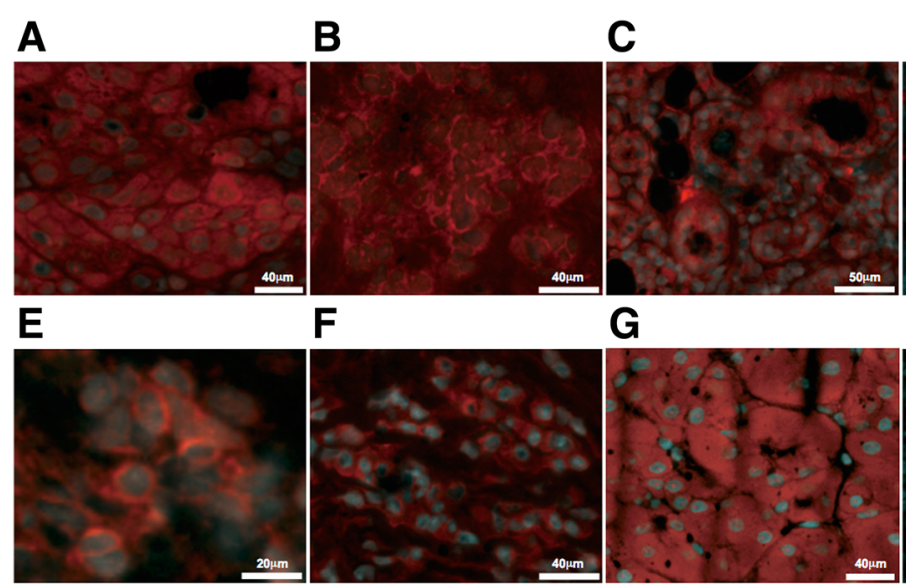

\section{D}

G

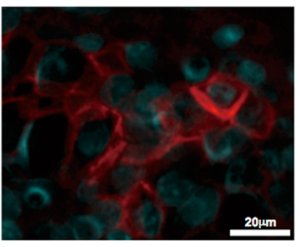

H

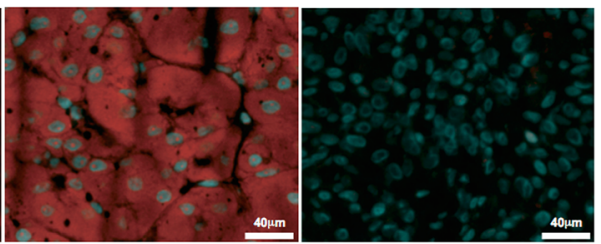

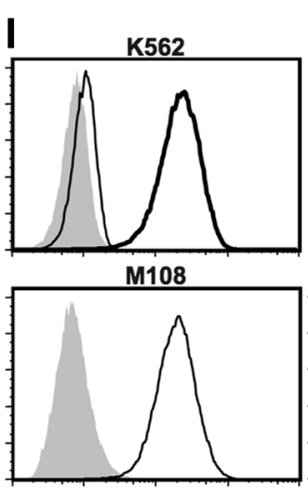

A253

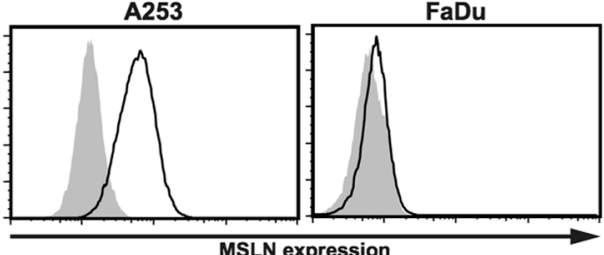

J
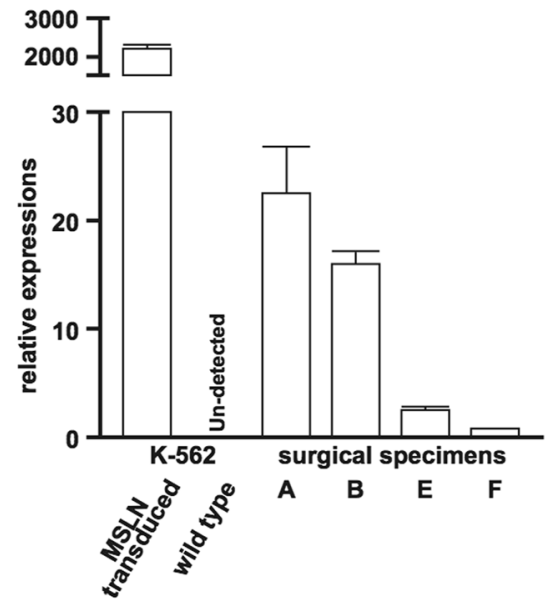

Fig. 1 MSLN expressions in the surgical samples obtained from the patients with various types of SGC and the various cancer cell lines. a-h Immunohistochemical images of mucoepidermoid carcinoma (a, case 12 and d, case 5), adenocarcinoma (b, case 13), salivary duct carcinoma (c, case 16 and f, case 15) and adenoid cystic carcinoma (e, case 11) are shown. Positive control tumor (g) and negative control pleomorphic adenoma (h, case 17) are also shown. The red and blue colors indicate MSLN and DAPI. i Histograms of MSLN expression on the various cancer cell lines analyzed by flow cytometry are shown. Gray shadows indicate isotype matched control. J RT-PCR analysis of MSLN were performed with case 12 (a), case 13 (b), case 11 (e) and case 15 (f). The MSLN-transduced or wild type K-562 cells were used for positive and negative control 


\section{Results}

\section{Expression of MSLN molecules in the salivary gland} cancer cells

First of all, we examined the tumor tissues to evaluate the proportions of MSLN-expressing cells. The surgical specimens of SGCs except for the case of squamous cell carcinoma expressed MSLN in a wide variety of the intensity (Table 1. and Fig. 1a-f). The mucoepidermoid carcinoma (Fig. 1a and d), the adenoid cystic carcinoma (Fig. 1c and e), the non-specific adenocarcinoma (Fig. 1b) and some of the salivary duct carcinoma samples (Fig. 1f) included more MSLN positive cells in the cancer tissues. However, the expression levels in the surgical specimens were highly variable even in the same specimen (Fig. 1c and f). The MSLN-expressing oncocytoma specimen that were benign epithelial tumor was utilized as positive control (Fig. 1g). MSLN-expressing cell was not detected in the pleomorphic adenoma that is the most frequent benign neoplasm in the salivary glands (Fig. 1h).

In the study with the several cell lines, MSLN was mildly expressed in the A-253 cells compared with the K562-MSLN cells and M108 cells those were positive controls, whereas the expression level in the A-253 cells was remarkably higher than that observed in the IMC-3 cells (derived from human maxillary squamous cell carcinoma) or $\mathrm{FaDu}$ cells (derived from human pharyngeal squamous cell carcinoma) (Fig. $1 \mathrm{i}$ and Additional file 1: Figure S1).

Moreover, the relative expressions (MSLN/GAPDH) of these surgical specimens (Fig. 1a, b, e and f) were measured by RT-PCR and MSLN expressions with wide variations were confirmed (Fig. 1j). The MSLN-transduced or wild type K-562 cells were used for positive and negative control.

\section{Preparation of MSLN-specific CAR redirected CD8 T cells and highly purified iNKT cells from primary human PBMCs}

SS1 scFv recognizes human MSLN with high binding affinity $(\mathrm{Kd}=0.7 \mathrm{nM})$ [45]. Two types of SS1 scFv-based

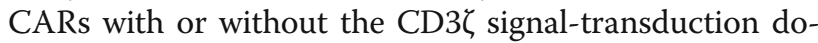
main and CD28/CD137 (4-1BB) intracellular domains in tandem $(\mathrm{SS} 1-28-\mathrm{BB}-\zeta$ or $\mathrm{SS} 1-\Delta \zeta)$ (Fig. $2 \mathrm{a}$ ) were lentivirally transduced into purified primary human CD8 $\mathrm{T}$ cells. SS1- $\Delta \zeta$ CAR expressing CD8 T cells were used for negative control. The transduction efficacy of these cells was analyzed using anti-mouse $F(a b) 2$ antibodies on the eighth day after stimulation. The proportion of CAR-expressing cells was $71 \%$ in the SS1-28-BB- $\zeta$ cells and $79 \%$ in the SS1- $\Delta \zeta$ cells (Fig. 2b). iNKT cells in PBMCs were expanded via $\alpha \mathrm{GalCer}$ stimulation and purified to reach a proportion of more than 95\% (Fig. 2c).

\section{The activation of CD8 CAR T cells was induced by the recognition of MSLN molecules on the surface of the SGC cells and augmented by the presence of iNKT cells}

The stimulation of SS1 CAR-expressing CD8 T cells by various tumor cell lines including A-253 did not increase the translocation of CD107a on the surface of the SS1- $\Delta \zeta$ transduced T cells because these CAR $\mathrm{T}$ cells could not transduce the activation signal after antigenic recognition (Fig. 3, first column). The CD107a mobilization of the $\mathrm{SS} 1-28-\mathrm{BB}-\zeta$ transduced

\section{A}

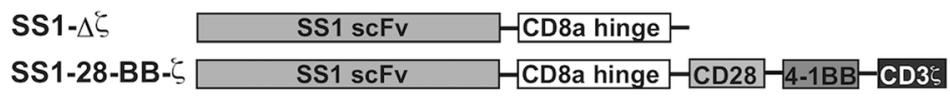

B

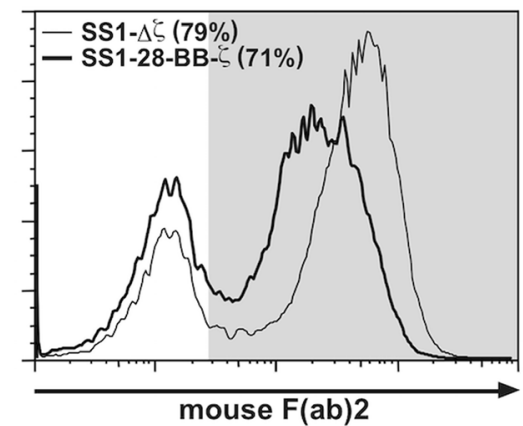

C

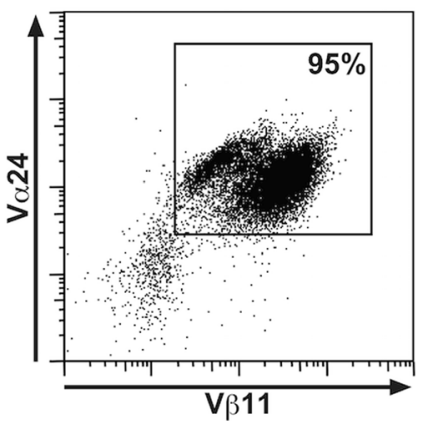

Fig. 2 Preparation of the anti-MSLN lentiviral vector engineered with CD8 T cells and highly purified iNKT cells. a Schematic representation of MSLN-binding CARs. For a binding-control CAR, a truncated TCR domain was utilized. $\mathbf{b}$ The expression levels of the SS1 scFv fusion proteins on human primary CD8 T cells were examined using flow cytometry. The thin and bold lines indicate SS1- $\triangle$ C and SS1-28-BBC, respectively. c iNKT cells were purified from human PBMCs stimulated with aGalCer for eight days 
cells was clearly induced by the stimulation with tumor cell lines used. The intensities of CD107 seemed to be dependent on the degree of the MSLN expression (Fig. 3, second column). iNKT cells increased the translocation of CD107a on the SS1$28-\mathrm{BB}-\zeta$ transduced cells, namely, the activation of these CAR T cells were augmented by the addition of iNKT cells compared with CAR T cells alone exposed to any types of cell lines. (Fig. 3, third column). iNKT cells could induce the activation of CAR $\mathrm{T}$ cells in some degree even in the absence of tumor cells (Fig. 3 , no tumor). These enhanced activations by iNKT cells were blocked by the treatment with IFNY blockade (Fig. 3, fourth column).

\section{Enhanced proliferation of CAR T cells after stimulation of} the SGC cells by activated iNKT cells

The proliferation of SS1- $\Delta \zeta$-expressing $\mathrm{T}$ cells was very low even after stimulation with the tumor cells expressing high levels of MSLN (Fig. 4 a, lower right column and $\mathrm{B}$, open bar). On the other hand, the significant expansion of SS1-28-BB- $\zeta$ T cells was detected after the similar stimulation (Fig. 4 b, light gray bar) and the degree was elevated by the co-culture with iNKT cells (Fig.

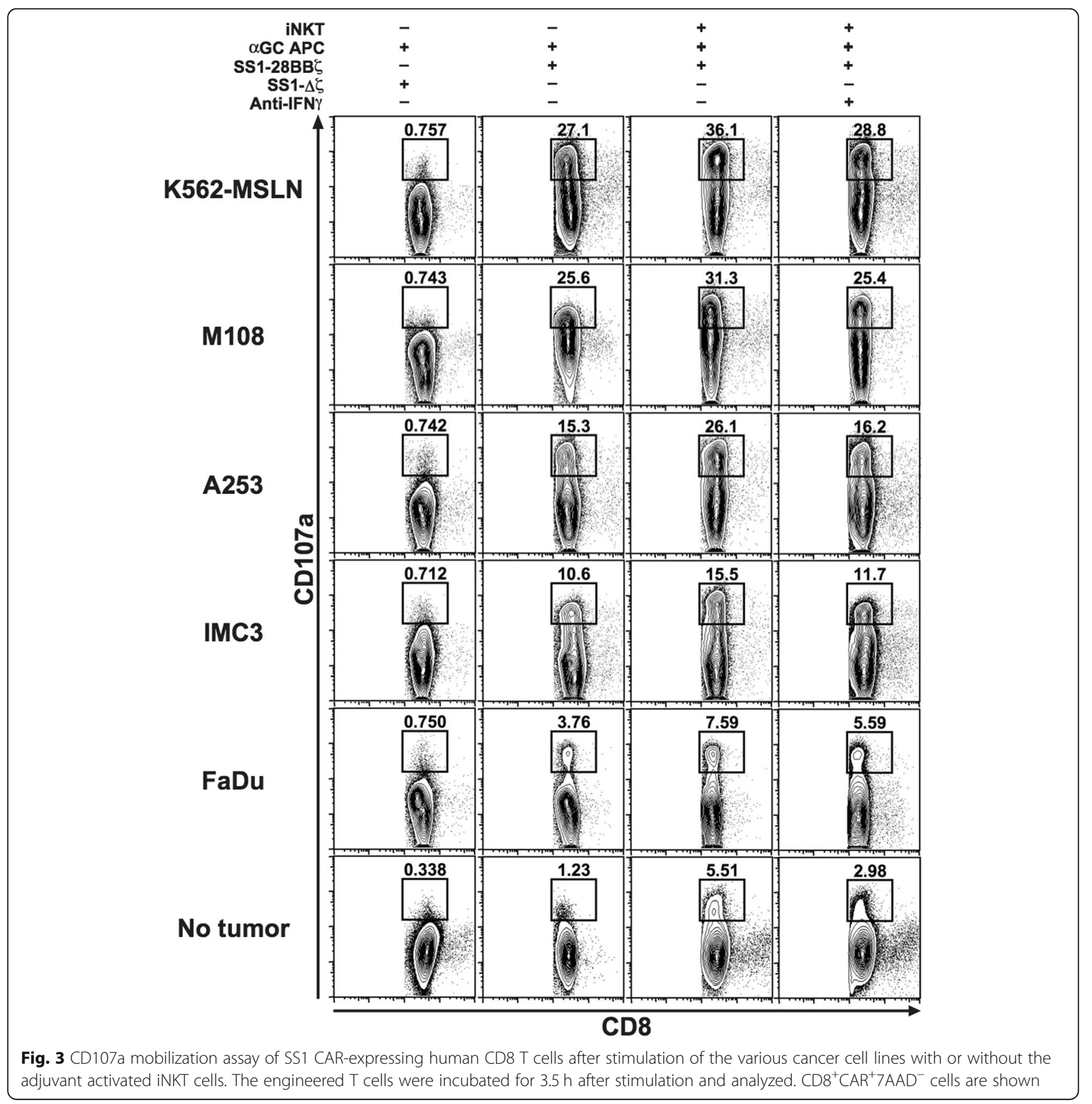


4 b, dark gray bar), Moreover, these amplifying effects by iNKT cells were completely blocked by the treatment with anti-IFNY (Fig. 4 b, solid bar).

\section{Augmented cytotoxicity of combination of CAR T cells} with iNKT cells against cancer cells expressing MSLN at a variety of intensities

In a chromium-release assay with the MSLN transduced K562 target cells, SS1-28-BB- $\zeta$ CAR-transduced human CD8 $\mathrm{T}$ cells lysed in a dose dependent manner, and moreover, the cytotoxicity was significantly enhanced by the combination with iNKT cells (Fig. 5a). A-253 cells that moderately expressed MSLN showed the resistant to the mono-treatment with CAR-redirected $\mathrm{T}$ cells or iNKT cells, whereas the combined use of CAR T cells with iNKT cells resulted in significantly enhanced killing activity against A-253 cells (Fig. 5b). Further, the IMC-3 cells which mildly expressed MSLN resisted to CAR $\mathrm{T}$ mono-treatment, however, the combined treatment of CAR T cells with iNKT cells showed significantly augmented killing activity similar to A-253 targets. (Fig. 5c). To FaDu cells that barely expressed MSLN, the killing activity of CAR $\mathrm{T}$ cell alone was obscure, however the activity of the combination with iNKT cells was significantly higher than that of iNKT cell mono-treatment (Fig. 5d).
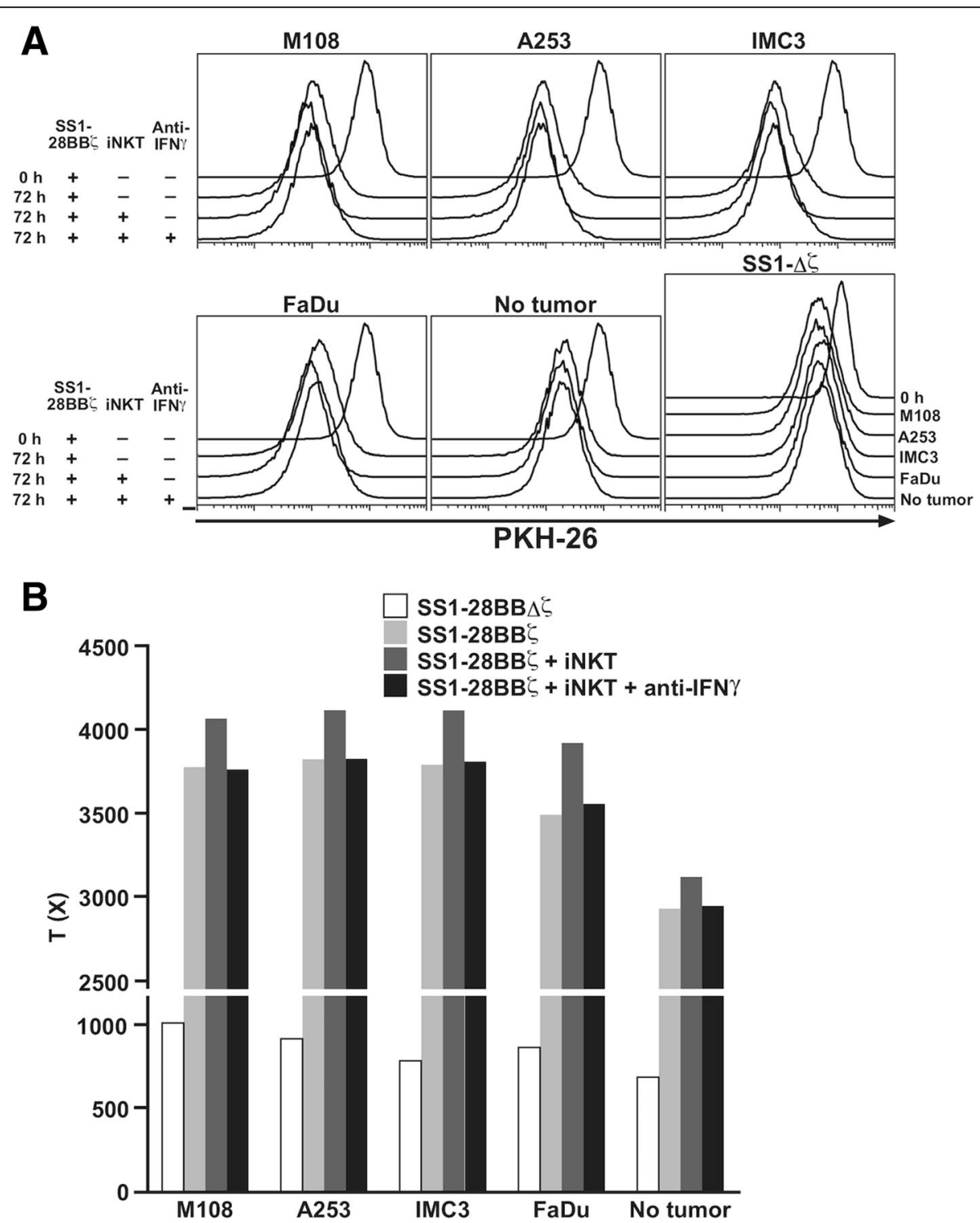

Fig. 4 Cellular proliferation of SS-1 CAR-transduced CD8 T cells. CAR-expressing CD8 T cells were stained with PKH26 and cultured for $72 \mathrm{~h}$ in the presence of M108, A-253, IMC3 and FaDu tumor cells. a A histogram of the PKH26 expression of CD8 $8^{+} C A R^{+} V a 24^{-} 7 A A D^{-}$cells and (b) proliferative index $(T(x))$ are shown 

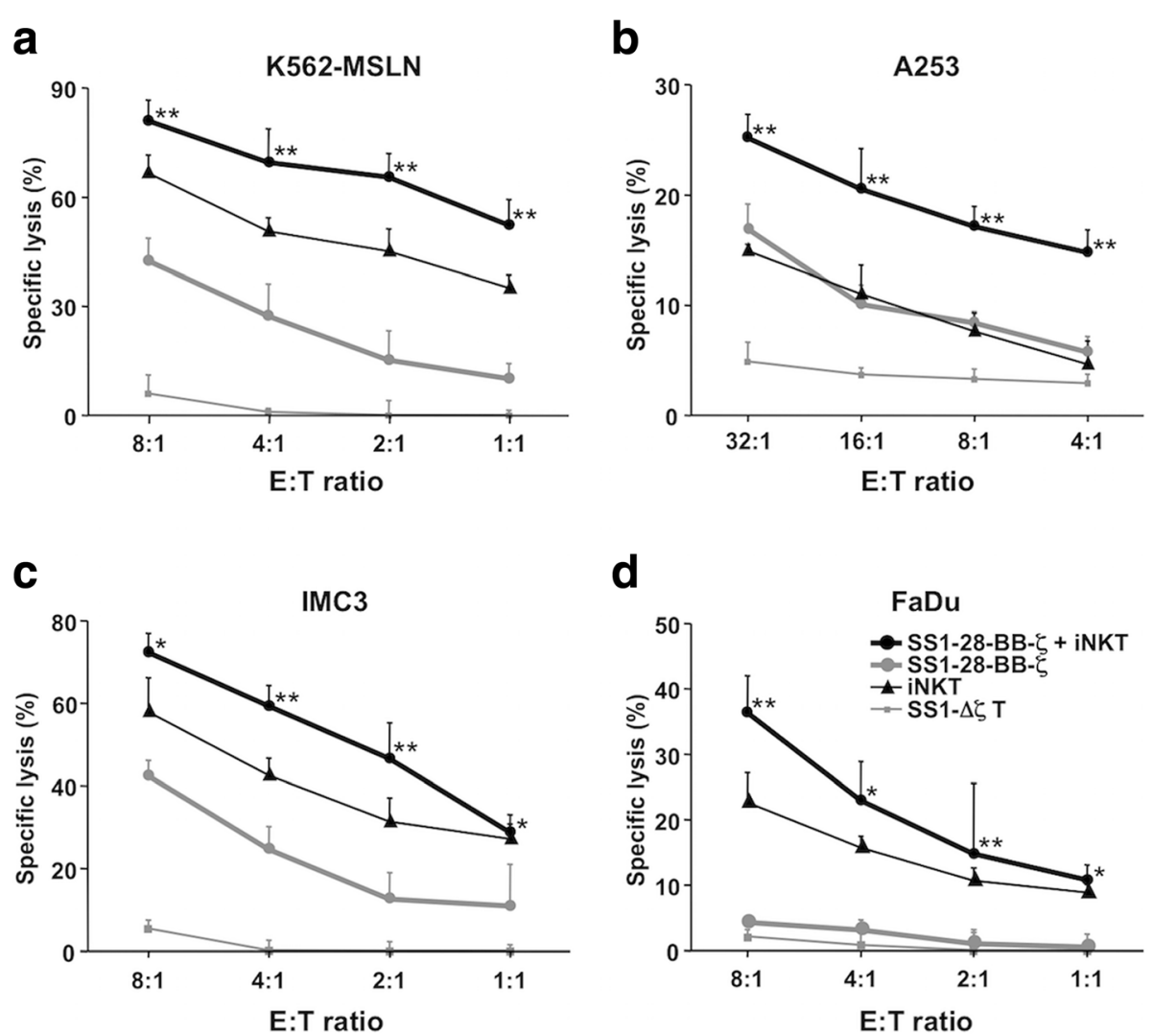

Fig. 5 Synergistically augmented cytotoxicity of the CAR-redirected CD8 T cells and activated iNKT cells against the cancer cells expressing MSLN molecules at various intensities. Four-hour chromium-51 release assays against four kinds of target cells, MSLN-transduced K562 (a), A-253 (b), IMC-3 (c) and FaDu (d) cells, were performed. The effector cells were SS1- $\Delta$ C or SS1-28-BBC and/or iNKT cells stimulated with aGalCer. Statistically significant differences are indicated by asterisks and daggers: ${ }^{*}, P<0.05 ;{ }^{*}, P<0.01=$

\section{Discussion}

The chimeric antigen receptor technique provides effector $\mathrm{T}$ cells with high concentrations of monoclonal antigen receptors and higher affinity and avidity than conventional $\mathrm{T}$ cell receptors. The adoptive transfer of CAR-expressing $\mathrm{T}$ cells has been shown to have dramatic efficacy in patients with hematological malignancies [20,46]; however, solid tumors are difficult to eradicate with CAR-expressing T cells. Because the target cancer antigens with sufficient affinity have not discovered, the activation and proliferation in tumor site of CAR-expressing $\mathrm{T}$ cells might not be enough [47]. Therefore, the development of novel adjuvant agents that enhance the anti-tumor activities of CAR T cells is critical for improving the therapeutic effects of cancer treatments.

MSLN is one of tumor antigen expressed on the various epithelial neoplasms [48]. In this study, we placed our focus on SGC that lacks effective treatments other than operation and investigated the potential of MSLN as a therapeutic target. The SGCs, which we examined, expressed MSLN except for the case of squamous cell carcinoma that is a rare in SGC. However, the expression levels varied among the surgical specimens, even within the same histological tumors, and moreover the mixtures of the cancer cells with varying expression of MSLN were observed in same sample. In order to examine the anti-tumor efficacy of MSLN-specific CAR-expressing CD8 $T$ cells against SGC, we utilized six kinds of cancer cell lines including A-253 cells, which were derived from salivary gland carcinoma and moderately expressed MSLN.

MSLN-specific third-generation CAR $\mathrm{T}$ cells were activated by and proliferated in response to the stimulation of cancer cells in a MSLN intensity-dependent manner. The activated CAR T cells showed significant cytotoxic effects against A-253 cells, however the effects were limited. Interestingly, the co-culture with iNKT cells could increase the activation as well as proliferation of CAR T cells and clearly enhanced the cytotoxicity. These amplifying effects of iNKT cells were detected in various tumor cells regardless of the expression level of MSLN. Especially, in the case of mono-treatment with CAR T cells against $\mathrm{FaDu}$ which barely expressed MSLN, although the CAR T cells certainly showed the activation and proliferation after the 
exposure to $\mathrm{FaDu}$ cells, any effective cytotoxic properties were not confirmed. However, the co-culture with iNKT cells significantly enhanced the activation and induced cytotoxicity of CAR T cells. In this study, iNKT cells could be expected to participate in the augmentation of the signal transduction and activations of MSLN specific CAR $\mathrm{T}$ cells after the MSLN recognition, followed by the enhanced cytotoxicity of CAR T cells. Because iNKT cells are known to be sensitive for a wide variety of tumor cells, the combination of CAR T cells with iNKT cells may be adapted for the cancer that weakly express the target molecule.

Although the detailed mechanisms of the enhanced cytotoxicity by the co-culture of CAR T cells with iNKT cells remain to be clarified, the IFNY produced from iNKT cells appears to play a critical role in this augmentation [49], as the treatment with anti-IFNy antibodies abrogated the potentiation. These results suggest that combination immunotherapy with CAR-expressing CD8 $\mathrm{T}$ cells and iNKT cells may be effective against cancer cells that express target molecules at low levels.

\section{Conclusions}

Further detailed in vivo studies need to be conducted to demonstrate the adjuvant effects of combined treatment of MSLN specific CAR T cells with iNKT cells and confirm the feasibility of this therapy. In addition, the adjuvant effects of iNKT cells may not be restricted to CAR T cells, but also be applicable to all forms of antigen-specific immunotherapy regimens containing antibody therapy.

\section{Additional file}

Additional file 1: Figure S1. Mean fluorescence intensities of MSLN expression on the various cancer cell lines. The mean fluorescence intensities shown in Fig. 1 (h) were calculated. The light gray bars indicate isotype matched controls, the dark gray bars indicate wild type cell lines and solid bar indicates MSLM transduced K562 cells. (TIFF 8911 kb)

\begin{abstract}
Abbreviations
7AAD: 7-aminoactinomycin D; APC: Antigen-presenting cell; CAR: Chimeric antigen receptor; CTL: Cytotoxic T lymphocyte; DC: Dendritic cells; FBS: Fetal bovine serum; HNSCC: Head and neck squamous cell carcinoma; IFNץ: Interferon-ү; IMRT: Intensity modulated radiation therapy; iNKT cell: Invariant natural killer T cell; MHC: Major histocompatibility complex; MSLN: Mesothelin; NK cell: Natural killer cell; PBMC: Peripheral mononuclear cells; SCC: Squamous cell carcinoma; SGC: Salivary gland cancers; aGalCer: agalactosylceramide
\end{abstract}

\section{Acknowledgments}

The authors thank Emi Sato and Hiromi Chiku (Department of Medical Immunology, Graduate School of Medicine, Chiba University, Chiba, Japan) for expert technical support and Prof. Carl H. June at University of Pennsylvania for advice.

\section{Funding}

This work was supported by MEXT KAKENHI Grant Number 17 K11376 and Takeda Science Foundation. The funding body had no role in the design of the study, the collection, analysis, and interpretation of data and in writing the manuscript.

\section{Availability of data and materials}

The datasets used and/or analyzed during the current study are available from the corresponding author upon reasonable request.

\section{Authors' contributions}

YM and NK designed and performed the experiments, analyzed data and wrote a draft of paper. DS and FI provided clinical perspective. SM, AS and TN discussed statistical analysis and helped to draft the manuscript. YO conceptualized the research, directed the study. All authors reviewed and edited the manuscript. All authors read and approve the final manuscript.

\section{Ethics approval and consent to participate}

This study protocol was approved by the Chiba University Institutional Review Board and written informed consent was obtained from each donor.

\section{Consent for publication}

Not applicable.

\section{Competing interests}

The authors declare that they have no competing interests.

\section{Publisher's Note}

Springer Nature remains neutral with regard to jurisdictional claims in published maps and institutional affiliations.

\section{Author details}

${ }^{1}$ Department of Otorhinolaryngology, Head and Neck Surgery, Graduate School of Medicine, Chiba University, 1-8-1 Inohana, Chuo-ku, Chiba 260-8670, Japan. ${ }^{2}$ Department of Medical Immunology, Graduate School of Medicine, Chiba University, Chiba, Japan. ${ }^{3}$ Department of Immunology, Graduate School of Medicine, Chiba University, Chiba, Japan.

Received: 4 August 2018 Accepted: 4 December 2018

Published online: 17 December 2018

\section{References}

1. Speight PM, Barrett AW. Salivary gland tumours. Oral Dis. 2002;8:229-40.

2. Brandwein MS, Ferlito A, Bradley PJ, Hille JJ, Rinaldo A. Diagnosis and classification of salivary neoplasms: pathologic challenges and relevance to clinical outcomes. Acta Otolaryngol. 2002;122:758-64.

3. Vander Poorten VL, Balm AJ, Hilgers FJ, Tan IB, Loftus-Coll BM, Keus RB, Hart AA. Prognostic factors for long term results of the treatment of patients with malignant submandibular gland tumors. Cancer. 1999;85:2255-64.

4. El-Naggar AK, Chan JKC, Grandis JR, Takata T, Slootweg PJ. WHO classification of head and neck Tumours WHO Classification of Tumours. 4th ed Volume 9; 2017.

5. Terhaard $\mathrm{CH}$, Lubsen $\mathrm{H}$, Van der Tweel I, Hilgers FJ, Eijkenboom WM, Marres HA, Tjho-Heslinga RE, de Jong JM, Roodenburg JL. Salivary gland carcinoma: independent prognostic factors for locoregional control, distant metastases, and overall survival: results of the Dutch head and neck oncology cooperative group. Head Neck. 2004;26:681-92.

6. Gormley WB, Sekhar LN, Wright DC, Olding M, Janecka IP, Snyderman CH, Richardson R. Management and long-term outcome of adenoid cystic carcinoma with intracranial extension: a neurosurgical perspective. Neurosurgery. 1996;38:1105-12.

7. Hosokawa Y, Shirato H, Kagei K, Hashimoto S, Nishioka T, Tei K, Ono M, Ohmori K, Kaneko M, Miyasaka K, Nakamura M. Role of radiotherapy for mucoepidermoid carcinoma of salivary gland. Oral Oncol. 1999;35:105-11.

8. Terhaard CH, Lubsen H, Rasch CR, Levendag PC, Kaanders HH, TjhoHeslinga RE, van Den Ende PL, Burlage F. The role of radiotherapy in the treatment of malignant salivary gland tumors. Int J Radiat Oncol Biol Phys. 2005;61:103-11.

9. Jensen AD, Nikoghosyan AV, Lossner K, Haberer T, Jäkel O, Münter MW, Debus JCOSMIC. A regimen of intensity modulated radiation therapy Plus dose-escalated, raster-scanned carbon ion boost for malignant salivary 
gland tumors: results of the prospective phase 2 trial. Int J Radiat Oncol Biol Phys. 2015;93:37-46.

10. Jingu K, Hasegawa A, Mizo JE, Bessho H, Morikawa T, Tsuji H, Tsujii H, Kamada T. Carbon ion radiotherapy for basal cell adenocarcinoma of the head and neck: preliminary report of six cases and review of the literature. Radiat Oncol. 2010;5:89.

11. Guzzo M, Locati LD, Prott FJ, Gatta G, McGurk M, Licitra L. Major and minor salivary gland tumors. Crit Rev Oncol Hematol. 2010;74:134-48.

12. Irving BA, Weiss A. The cytoplasmic domain of the T cell receptor zeta chain is sufficient to couple to receptor-associated signal transduction pathways. Cell. 1991;64:891-901.

13. Eshhar Z, Waks T, Gross G, Schindler DG. Specific activation and targeting of cytotoxic lymphocytes through chimeric single chains consisting of antibodybinding domains and the gamma or zeta subunits of the immunoglobulin and T-cell receptors. Proc Natl Acad Sci U S A. 1993:90:720-4.

14. Sadelain M, Riviere I, Brentjens R. Targeting tumours with genetically enhanced T lymphocytes. Nat Rev Cancer. 2003;3:35-45.

15. Kershaw MH, Westwood JA, Darcy PK. Gene-engineered T cells for cancer therapy. Nat Rev Cancer. 2013;13:525-41.

16. June CH. Principles of adoptive T cell cancer therapy. J Clin Invest. 2007;117: 1204-12.

17. Kohn DB, Dotti G, Brentjens R, Savoldo B, Jensen M, Cooper LJ, June CH, Rosenberg S, Sadelain M. Heslop HE. CARs on track in the clinic. Mol Ther. 2011;19:432-8.

18. June CH. Adoptive T cell therapy for cancer in the clinic. J Clin Invest. 2007; 117:1466-76.

19. June $\mathrm{CH}$, Blazar BR, Riley JL. Engineering lymphocyte subsets: tools trials and tribulations. Nat Rev Immunol. 2009;9:704-16.

20. Kalos M, Levine BL, Porter DL, Katz S, Grupp SA, Bagg A. June CH. T cells with chimeric antigen receptors have potent antitumor effects and can establish memory in patients with advanced leukemia. Sci Transl Med. 2011;3:95ra73.

21. Argani P, lacobuzio-Donahue C, Ryu B, Rosty C, Goggins M, Wilentz RE, Murugesan SR, Leach SD, Jaffee E, Yeo CJ, Cameron JL, Kern SE, Hruban RH. Mesothelin is overexpressed in the vast majority of ductal adenocarcinomas of the pancreas: identification of a new pancreatic cancer marker by serial analysis of gene expression (SAGE). Clin Cancer Res. 2001;7:3862-8.

22. Hassan R, Bera T, Pastan I. Mesothelin: a new target for immunotherapy. Clin Cancer Res. 2004;10:3937-42.

23. Ho M, Bera TK, Willingham MC, Onda M, Hassan R, FitzGerald D, Pastan I. Mesothelin expression in human lung cancer. Clin Cancer Res. 2007;13:1571-5.

24. Pastan I, Hassan R. Discovery of mesothelin and exploiting it as a target for immunotherapy. Cancer Res. 2014;74:2907-12.

25. Carpenito C, Milone MC, Hassan R, Simonet JC, Lakhal M, Suhoski MM, Varela-Rohena A, Haines KM, Heitjan DF, Albelda SM, Carroll RG, Riley JL, Pastan I, June CH. Control of large, established tumor xenografts with genetically retargeted human T cells containing CD28 and CD137 domains. Proc Natl Acad Sci U S A. 2009;106:3360-5.

26. Textor A, Listopad JJ, Wührmann LL, Perez C, Kruschinski A, Chmielewski M, Abken H, Blankenstein T, Charo J. Efficacy of CAR T-cell therapy in large tumors relies upon stromal targeting by IFNy. Cancer Res. 2014;74:6796-805.

27. Rossig C. Extending the chimeric receptor-based T-cell targeting strategy to solid tumors. Oncoimmunology. 2013;2:26091.

28. Bendelac A, Lantz O, Quimby ME, Yewdell JW, Bennink JR, Brutkiewicz RR. CD1 recognition by mouse NK1 ${ }^{+}$T lymphocytes. Science. 1995;268:863-5.

29. Kawano T, Cui J, Koezuka Y, Toura I, Kaneko Y, Motoki K, Ueno H, Nakagawa R, Sato H, Kondo E, Koseki H, Taniguchi M. CD1d-restricted and TCRmediated activation of Va14 NKT cells by glycosylceramides. Science. 1997; 278:1626-9.

30. Spada FM, Koezuka Y, Porcelli SA. CD1d-restricted recognition of synthetic glycolipid antigens by human natural killer T cells. J Exp Med. 1998;188:1529-34

31. Taniguchi M, Harada M, Kojo S, Nakayama T, Wakao H. The regulatory role of Va14 NKT cells in innate and acquired immune response. Annu Rev Immunol. 2003;21:483-513.

32. Brigl M, Brenner MB. CD1: antigen presentation and T cell function. Annu Rev Immunol. 2004;22:817-90.

33. Uchida T, Horiguchi S, Tanaka Y, Yamamoto H, Kunii N, Motohashi S, Taniguchi M, Nakayama T, Okamoto Y. Phase I study of agalactosylceramide-pulsed antigen presenting cells administration to the nasal submucosa in unresectable or recurrent head and neck cancer. Cancer Immunol Immunother. 2008;57:337-45.
34. Kunii N, Horiguchi S, Motohashi S, Yamamoto H, Ueno N, Yamamoto S, Sakurai D, Taniguchi M, Nakayama T, Okamoto Y. Combination therapy of in vitro-expanded natural killer T cells and a-galactosylceramide-pulsed antigen-presenting cells in patients with recurrent head and neck carcinoma. Cancer Sci. 2009;100:1092-8.

35. Yamasaki K, Horiguchi S, Kurosaki M, Kunii N, Nagato K, Hanaoka H, Shimizu N, Ueno N, Yamamoto S, Taniguchi M, Motohashi S, Nakayama T, Okamoto Y. Induction of NKT cell-specific immune responses in cancer tissues after NKT cell-targeted adoptive immunotherapy. Clin Immunol. 2011;138:255-65.

36. Kurosaki M, Horiguchi S, Yamasaki K, Uchida Y, Motohashi S, Nakayama T, Sugimoto A, Okamoto Y. Migration and immunological reaction after the administration of aGalCer-pulsed antigen-presenting cells into the submucosa of patients with head and neck cancer. Cancer Immunol Immunother. 2011;60:207-15.

37. Nakagawa R, Nagafune I, Tazunoki Y, Ehara H, Tomura H, lijima R, Motoki K, Kamishohara M, Seki S. Mechanisms of the antimetastatic effect in the liver and of the hepatocyte injury induced by a-galactosylceramide in mice. J Immunol. 2001;166:6578-84.

38. Smyth MJ, Crowe NY, Pellicci DG, Kyparissoudis K, Kelly JM, Takeda K, Yagita $\mathrm{H}$, Godfrey DI. Sequential production of interferon- $\gamma$ by NK1.1 $1^{+} \mathrm{T}$ cells and natural killer cells is essential for the antimetastatic effect of agalactosylceramide. Blood. 2002;99:1259-66.

39. Honda A, Hirose M, Hatori M, Matoba S, Miyoshi H, Inoue K, Ogura A. Generation of induced pluripotent stem cells in rabbits: potential experimental models for human regenerative medicine. J Biol Chem. 2010; 285:31362-9.

40. Motohashi S, Ishikawa A, Ishikawa E, Otsuji M, lizasa T, Hanaoka H, Shimizu N, Horiguchi S, Okamoto Y, Fujii S, Taniguchi M, Fujisawa T. Nakayama T. a phase I study of in vitro expanded natural killer T cells in patients with advanced and recurrent non-small cell lung cancer. Clin Cancer Res. 2006; 12:6079-86.

41. Kidoya H, Kunii N, Naito H, Muramatsu F, Okamoto Y, Nakayama T, Takakura $\mathrm{N}$. The apelin/APJ system induces maturation of the tumor vasculature and improves the efficiency of immune therapy. Oncogene. 2012;31:3254-64.

42. Kunii N, Zhao Y, Jiang S, Liu X, Scholler J, Balagopalan L, Samelson LE, Milone MC, June CH. Enhanced function of redirected human T cells expressing linker for activation of $\mathrm{T}$ cells that is resistant to ubiquitylation. Hum Gene Ther. 2013;24:27-37.

43. Roederer M, Moore W, Treister A, Hardy RR, Herzenberg LA. Probability binning comparison: a metric for quantitating multivariate distribution differences. Cytometry. 2001;45:47-55.

44. Munson ME. An improved technique for calculating relative response in cellular proliferation experiments. Cytometry A. 2010;77:909-10.

45. Li Q, Verschraegen CF, Mendoza J, Hassan R. Cytotoxic activity of the recombinant anti-mesothelin immunotoxin, SS1(dsFv)PE38, towards tumor cell lines established from ascites of patients with peritoneal mesotheliomas. Anticancer Res. 2004;24:1327-35.

46. Porter DL, Levine BL, Kalos M, Bagg A, June CH. Chimeric antigen receptormodified T cells in chronic lymphoid leukemia. N Engl J Med. 2011;365:725-33.

47. Adusumilli PS, Cherkassky L, Villena-Vargas J, Colovos C, Servais E, Plotkin J, Jones DR, Sadelain M. Regional delivery of mesothelin-targeted CAR T cell therapy generates potent and long-lasting CD4-dependent tumor immunity. Sci Transl Med. 2014;6:261ra151.

48. Beatty GL, Haas AR, Maus MV, Torigian DA, Soulen MC, Plesa G, Chew A, Zhao Y, Levine BL, Albelda SM, Kalos M, June CH. Mesothelin-specific chimeric antigen receptor mRNA-engineered T cells induce anti-tumor activity in solid malignancies. Cancer Immunol Res. 2014;2:112-20.

49. Motohashi S, Kobayashi S, Ito T, Magara KK, Mikuni O, Kamada N, lizasa T, Nakayama T, Fujisawa T, Taniguchi M. Preserved IFN- $\gamma$ production of circulating Va24 NKT cells in primary lung cancer patients. Int J Cancer. 2002;102:159-65. 